bile duct in those at low risk from open surgery (mostly young patients). It seems unreasonable to subject such patients to the risks of insufflation and trocar injuries and to the dangers of laparoscopic dissection in Calot's triangle only to convert to open operation when cholangiography shows bile duct stones. Preoperative intravenous cholangiography for this low risk group therefore seems a superior strategy. It is highly sensitive, and for those in whom the ductal anatomy is not clearly seen operative cholangiography remains possible. Those with proved choledocholithiasis might then be offered open surgery or might choose to risk the increased morbidity and mortality of endoscopic treatment on the basis of truly informed consen rather than be subjected to it by a surgeon "under considerable psychological pressure not to convert to an open procedure."

No data are given to support the economic argument. This is not surprising as reliable data are largely unavailable. The economic debate is complex and confounded by variable rates of technical failure, conversion to open surgery, and hospital stay as well as variable costs, complication rates, and skill in endoscopic retrograde cholangiopancreatography. It is probably safe to conclude that neither strategy could be excluded on the grounds of overall cost alone. Nevertheless, preoperative identification of patients with choledocholithiasis who the surgeon thinks would be best treated by open surgery would decrease theatre costs and improve the allocation of theatre time.

FRED J MULLAN $S$ TERENCE IRWIN

Ward 2 Surgical Unit,

Belfast City Hospital,

Belfast BT9 7AB

1 Scott-Coombes D, Thompson JN. Bile duct stones and laparoscopic cholecystectomy. BMF 1991;303:1281-2. (23 November.)

SIR,-Hammersmith Hospital has traditionally eschewed endoscopy for both the diagnosis and treatment of biliary disorders, but we are dismayed that David Scott-Coombes and Jeremy N Thompson maintain this policy into the 1990s for bile duct stones and laparoscopic cholecystectomy.

For preoperative diagnosis of bile duct stones they favour intravenous cholangiography over endoscopic retrograde cholangiography. We do not share their confidence in intravenous cholangiography, which in previous series had an appreciable technical failure rate and was difficult to perform and to interpret. ${ }^{23}$ Although more invasive, endoscopy is more accurate, and hence intravenous cholangiography has all but disappeared in centres with reliable endoscopic retrograde cholangiopancreatography. Most radiologists working in such centres will be unconvinced by the attempts to resurrect intravenous cholangiography that are cited ${ }^{45}$ and would not welcome its reintroduction.

Scott-Coombes and Thompson also prefer open cholecystectomy to preoperative endoscopic bile duct clearance followed by laparoscopic cholecystectomy for fit patients with bile duct stones. Their rationale for this policy seems to derive from a single study of preoperative endoscopic sphincterotomy and cholecystectomy versus surgery alone for common bile duct stones, which did not show any clinical advantage for patients treated by the former protocol. ${ }^{6}$ This study is marred, however, by an unacceptably high complication rate after endoscopic sphincterotomy, principally because of a lack of endoscopic drainage for failed stone clearance, which is mandatory in current practice. They fail to quote other studies which have found endoscopic sphincterotomy before cholecystectomy acceptable ${ }^{\mathrm{x}-11}$ or to mention that all the above studies have shown a shorter inpatient stay with preoperative endoscopic sphincterotomy and avoidance of explora- tion of the bile duct. These economic factors will be even more relevant for laparoscopic cholecystectomy.

Endoscopic retrograde cholangiopancreatography can be used both to diagnose bile duct stones and to remove $90 \%$ of them at a single procedure, ${ }^{7}$ and this is its major advantage over alternatives. We carry out preoperative endoscopic retrograde cholangiopancreatography and sphinc terotomy for patients due to have laparoscopic cholecystectomy in whom bile duct stones are likely or are known to be present. Such a policy is also recommended from the United States. ${ }^{1}$

It is to be hoped that with time these uncertainties will be answered by carefully conducted prospective trials, but interim guidelines are clearly necessary. Though the surgical and radiological skill in biliary disease at Hammersmith Hospital is second to none, endoscopy has been ignored, and we consider that a more balanced approach should be presented in the editorial columns of the $B M \mathcal{F}$.

COLIN AINLEY MICHAEL GLYNN JANET MURFITT DAVID MACLEAN

Royal London Hospital

London El 1BB

1 Scott-Coombes D, Thompson JN. Bile duct stones and laparoscopic cholecystectomy. BMF 1991;303:1281-2. (23 November.

2 Goodman MW, Ansel HJ, Vennes JA, Lasser RB, Silvis SE. Is intravenous cholangiography still useful? Gastroenterology 1980;79:642-5.

3 Darnborough A, Geffen J. Drip infusion cholangiography. Br f Radiol 1966;39:827-33.

4 Huddy SPJ, Southam JA. Is intravenous cholangiography an alternative to the routine peroperative cholangiogram? Postgrad Med F 1989;85:896-9.

5 Daly J, Fitzgerald T, Simpson CJ. Preoperative intravenous cholangiography as an alternative to routine operative cholangiography in elective cholecystectomy. Clin Radiol 1987;38: 181-3.

6 Neoptolemos JP, Carre-Locke DL, Fossard DP. Prospective randomised trial of preoperative endoscopic sphincterotomy versus surgery alone for common bile duct stones. $B M \mathcal{J}$ 1987;294:470-4.

7 Vaira D, D'Anna L, Ainley C, Dowsett J, Williams S, Baillie J, et al. Endoscopic sphincterotomy in 1000 consecutive patients. Lancet 1989;ii:431-4.

8 Miller BM, Kozarek RA, Ryan JA, Ball TJ, Traverso LW. Surgical versus endoscopic management of common bile duct Surgical versus endoscopic manage

9 Heinerman PM, Boeckl O, Pimpl W. Selective ERCP and preoperative endoscopic stone removal in bile duct surgery. Arch Surg 1989;209:267-72.

10 Van Stiegmann G, Pearlman NW, Goff JS, Norton LW. Endoscopic cholangiography and stone removal prior to cholecystectomy. Arch Surg 1989;124:787-9.

11 Ponchon T, Bory R, Chavaillon A, Fouillet P. Biliary lithiasis: combined endoscopic and surgical treatment. Endoscopy 1989;21:15-8.

12 Cotton PB, Baillie J, Pappas TN, Meyers WS. Laparoscopic cholecystectomy and the biliary endoscopist. Gastrontest Endosc 1991;37:94-7.

\section{Peak bone mass and bone loss in postmenopausal osteoporosis}

Sir,-Marc A Hansen and colleagues raise the interesting possibility that women at risk of osteoporosis may be identified by biochemical markers which predict rapid bone loss. 'I believe, however, that there may be a rather mundane explanation for their findings that they have not excluded. In their original publication the regression coefficient relating observed bone loss to predicted bone loss was three times higher than that in the current report. ${ }^{2}$ This eloquently shows that bone loss in the cohort studied slowed dramatically over the 12 years of observation.

In our study of postmenopausal bone loss in a similar cohort, recruited between nine months and three years after their last menstrual period, we have found that the mean rate of spinal bone loss, initially $3 \%$ a year as measured by dual photon absorptiometry, slows appreciably within three years after the menopause ${ }^{3}$ t the mean rate three years after the menopause had fallen to $2 \%$ a year and at five years it had fallen to only $1 \cdot 5 \%$ a year Prince et al recently reported similar results: they found that time since the menopause was an important determinant of the rate of loss of bone in the forearm in their controlled intervention study in women after the menopause.

I therefore suggest that Hansen and colleagues' data should be reanalysed with time since the menopause as a further independent determinant of future cumulative bone loss. It would be considerably easier to ask when a woman's last menstrual period was than to perform multiple biochemical tests on blood and urine samples to predict bone loss over the next decade.

J REEVE

Bone Disease Research Group

Clinical Research Centre,

Harrow, Middlesex HAl 3UJ

1 Hansen MA, Overgaard K, Riis B, Christiansen C. Role of peak bone mass and bone loss in postmenopausal osteoporosis: 12 bone mass and bone loss in postmenopausal o.

year study. BMF 1991;303:961-4. (19 October.)

Christiansen B, Riis BJ, Rodbro P. Prediction of rapid bone loss in postmenopausal women. Lancet 1987;ii:1105-8.

Reeve J, Green JR, Hesp R, Justice J, Nicholls A, Charlett A, et al. Determinants of axial bone loss in the early post menopause: the Harrow postmenopausal bone loss study. In: Christiansen C, Overgaard K, eds. Osteoporosis 1990. Copenhagen: Osteopress, 1990:101-3.

4 Prince RL, Smith M, Dick IM, Price RI, Webb PG, Henderson NK, et al. Prevention of postmenopausal osteoporosis. A comparative study of exercise, calcium supplementation, and hormone-replacement therapy. $N$ Engl f Med 1991-325: $1189-95$.

AUTHORS' REPLY, - J Reeve's comments need some clarification. We agree that it is considerably easier to ask about a woman's last menstrual period than to perform multiple biochemical tests, but there are no published reports to support the suggestion that bone loss over the next decade is to any extent related to age at the menopause. We did examine the menopause as an independent determinant of future bone loss, but there was no significant correlation.

Many data have shown that the rate of bone loss after the menopause is exponential, but the rate of loss during the first five to seven years is for practical reasons linear..$^{1.2}$ Reeve's data on bone loss were obtained with dual photon absorptiometry, which is an obsolete method; it has been known for years that the inaccuracy of this method makes it unacceptable for longitudinal studies.

The important diagnostic problem is how we find the women at risk of developing osteoporosis. There is now a consensus in the scientific community that a precise and accurate measurement of bone mass combined with an estimation of bone loss can identify the women at risk.

M A HANSEN K OVERGAARD

B J RIIS

C CHRISTIANSEN

Department of Clinical Chemistry,

Glostrup Hospital,

DK-2600 Glostrup

Denmark

1 Nilas L, Gotfredsen A, Hadberg A, Christiansen C. Age-related bone loss in women evaluated by the single- and dual photon technique. Bone Miner 1988;4:95-103.

2 Hui SL, Slemenda CW, Johnston CC, Appledorn CR. Effects of age and menopause on vertebral bone density. Bone Miner 1987;2:141-6.

3 Nordin BEC, Polley KJ. Metabolic consequences of the menopause. A cross-sectional, longitudinal, and intervention study on 557 normal postmenopausal women. Calcif Tissue Int on 557 normal 1987 ;suppl 1:1-58.

4 Nilas L, Hassager C, Christiansen C. Long-term precision of dual photon absorptiometry in the lumbar spine in clinical settings. Bone Miner 1988;3:305-15.

5 Ross PD, Wasnich RD, Vogel JM. Precision error in dual-photon absorptiometry related to source age. Radiology 1988;166: $523-7$

6 Consensus development conference: prophylaxis and treatment of osteoporosis. Am J Med 1991;90:107-10.

SIR,-Marc A Hansen and colleagues have performed a valuable study in showing that a single 